\section{Check before you travel: Zika virus - another emerging global health threat}

\author{
C. Scully ${ }^{* 1}$ and A. Robinson ${ }^{2}$
}

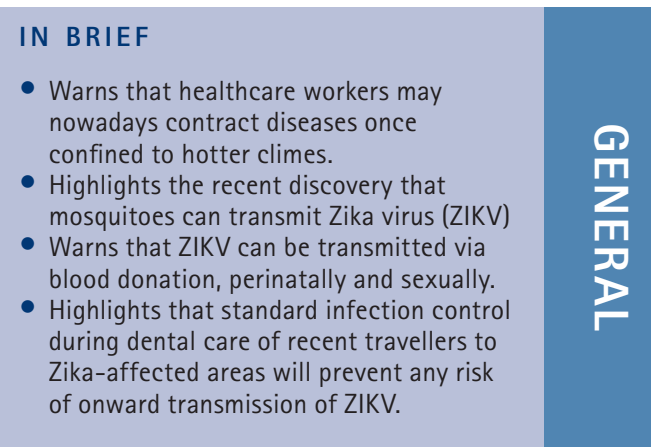

\begin{abstract}
We now know that mosquitoes can transmit arboviruses such as the Zika virus (ZIKV) which is pandemic in Latin America. In order to avoid infection it is advised to avoid mosquitoes, but ZIKV can also be transmitted through blood donation, perinatally and sexually and has been detected in urine and saliva. Prevention against mosquito bites (particularly daytime bites) is best offered by avoiding mosquitoes and bites. To prevent the risk of transmission of ZIKV, standard infection control of all recent travellers to Zika affected areas should be conducted during dental care. This article will discuss how healthcare workers could contract diseases especially whilst working in the tropics or subtropics due to disease vectors such as mosquitoes and suggests prevention measures for this group.
\end{abstract}

\section{INTRODUCTION}

UK healthcare workers, including dental staff and students, may nowadays contract diseases once confined to climes hotter than in the UK, by working or travelling in the tropics and sub-tropics or remote locations, or caring for patients from those areas and becoming exposed to disease vectors. At the same time, global warming is facilitating the spread of many vectors outwith the tropics/sub-tropics.

The attractions of travel to exotic areas often outweigh any thought of risk from diseases: only about one half of travellers/holidaymakers seek professional or other advice, ${ }^{1}$ or will view brochures that carry health warnings (http://www.nhs.uk/livewell/ travelhealth/Pages/Travelhealthhome.aspx). There are many vectors (apart from humans), and most who visit the tropics will experience mosquitoes bites.

Mosquitoes spread many infectious diseases from several different classes of microorganisms, including viruses and parasites (http://www.mosquito.org/mosquito-bornediseases). Malaria, the most widespread mosquito-borne disease, affects 350-500 million people globally each year with over 400,000 deaths: sub-Saharan Africa has most infections.

\footnotetext{
${ }^{1}$ University College London, London; ${ }^{2}$ Faculty of Dentistry, National University of Singapore.

${ }^{*}$ Correspondence to: Professor C. Scully

Email: crispian.scully@ucl.ac.uk
}

Accepted 10 February 2016

DOI: 10.1038/sj.bdj.2016.182

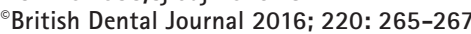

Mosquitoes can also transmit arbo (arthropod-borne) viruses, notably yellow fever found predominantly in tropical and subtropical areas in South America and Africa; a vaccine against yellow fever is available and is needed for anyone travelling to endemic areas. Mosquitoes can also transmit dengue fever (which infects nearly 400 million people each year, causing an estimated 25,000 deaths). Two related mosquito species, Aedes aegypti (the yellow fever mosquito) and Aedes albopictus (the Asian tiger mosquito) transmit yellow fever, dengue, and chikungunya (an infection similar to dengue). Relatively recently it has become evident that mosquitoes can also transmit other arboviruses such as West Nile and Zika. ${ }^{2}$

Globally, dengue is currently the most common arboviral disease, with $40 \%$ of the world's population living in areas with dengue virus transmission. Over the past two decades dengue has spread from the southern hemisphere (aggressively in the 1990s). West Nile virus emerged in 1999 and chikungunya emerged in 2013. ${ }^{3,4}$ Zika virus (ZIKV) is the latest emerging arbovirus threat to global health security. ${ }^{5}$

\section{ZIKA VIRUS}

Zika virus (ZIKV) is spread primarily to people through mosquito bites. Most known Zika virus vectors are sylvatic (pertaining to forested areas) Aedes mosquitoes from Africa where Zika was first isolated. Ae. aegypti is the only known vector outside Africa, and Ae. albopictus has for long also been a suspected Zika vector being capable of transmitting more than 20 arboviruses including chikungunya. $^{2}$

ZIKV has been isolated from blood of Zika victims, and can be transmitted through blood donation - but this is an infrequent mechanism. ${ }^{6}$ Perinatal transmission has been reported. ${ }^{7}$ Zika has also been isolated in semen, and rare cases of possible person-to-person sexual transmission have been described. ${ }^{8,9}$ Zika virus has also been detected in urine and saliva. ${ }^{10}$ However, there is no airborne transmission known and to date transmission via breastfeeding has not been reported.

ZIKV, a neurotropic flavivirus, was first isolated in 1947 from a research monkey in a cage in the Ugandan Zika forest (hence the name) and then, from 1951 through 1981, human infection was reported from within a narrow equatorial belt from Africa to Asia - from Nigeria and other African countries such as the Central African Republic, Egypt, Gabon, Sierra Leone, Tanzania and Uganda, as well as in parts of Asia including India, Indonesia, Malaysia, the Philippines, Thailand, and Mexico, Venezuela, and Vietnam. ${ }^{5,11}$ ZIKV spread across the Pacific ocean to French Polynesia, coming to attention when it caused a major outbreak in 2007 in the Island of Yap where 75\% of the population were infected. ${ }^{12}$ By 3 March 2014, Chile confirmed a case of indigenous transmission of Zika virus on its Easter Island, ${ }^{13}$ where the virus continues to be detected and by 2015 it had also spread to Brazil. In May 
2015, the public health authorities of Brazil, the Pan American Health Organization (PAHO), confirmed the transmission of Zika virus around Recife in the northeast (http://www.cdc.gov/zika/). Since October 2015, other countries and territories of the Americas have reported the presence of Zika and in Latin America it has now reached pandemic levels, with a wide geographic distribution in Central America, the Caribbean, and South America in several countries and territories including Brazil, Colombia, El Salvador, French Guiana, Guatemala, Haiti, Honduras, Martinique, Mexico, Panama, Paraguay, Suriname, Venezuela, Puerto Rico, U.S. Virgin Islands, Dominican Republic, Barbados, Bolivia, Ecuador, Guadeloupe, Saint Martin, Guyana, Cape Verde and the US territory of American Samoa. (see updated list [www.paho.org/zikavirus]). Currently (February 2016), Zika viral transmission has been reported in a total of 44 countries with Brazil having the most number of cases (estimated between 497,593 and 1,482,701 cases) and Colombia, the next most affected area, had 20297 cases reported from October 2015 to the end of January 2016. ${ }^{14}$ Cases of ZIKV infection, mainly in travellers have started to be recognised in North America (USA) and Europe (UK, Italy). ${ }^{17-17}$ Zika is spreading rapidly - with approximately three dozen cases in the continental United States reported among returning travellers.

\section{ZIKA ILLNESS AND MICROCEPHALY}

Zika illness is similar to a mild dengue infection with a fever, maculopapular rash, arthralgias (joint pains), and conjunctivitis (red eyes). Starting 3-15 days after exposure to Zika virus, the illness lasts from three or four days to a week (http://www. who.int/mediacentre/factsheets/zika/en/). Most infections are mild or asymptomatic and Zika is only rarely lethal in adults, and then usually due to neurological complications such as Guillain-Barré syndrome (GBS).

Severe disease requiring hospitalisation is uncommon but the outbreak in Brazil, particularly in Pernambuco state, led to reports of poor pregnancy outcomes, ranging from abortions to babies born with birth defects (notably microcephaly [small brain with learning defects]), and in adults Zika can induce GBS ${ }^{18}$ (http://www.who.int/emergencies/zika-virus/ microcephaly/en/). The possible association of ZIKV and microcephaly is controversial, however, since the latter is much more common in Brazil than in Colombia - where ZIKV infection is also high. A total of seven countries have reported increases in the incidence of microcephaly and GBS cases in tandem with the Zika virus outbreak. This has prompted WHO to declare a Public Health Emergency of International Concern on 1 February 2016 (http://www.who.int/mediacentre/news/ statements/2016/1st-emergency-committeezika/en/). In, for example, Brazil, while the number of annual cases of microcephaly were consistently below 200, between mid-2015 and 30 January 2016, 4,783 suspected cases of microcephaly were reported. 1,103 of these cases have completed investigations and 404 cases (36.2\%) were confirmed cases of microcephaly, with the Zika virus identified in 17 of these cases; 709 cases were discarded and 3,670 suspected cases are pending further confirmatory investigations. ${ }^{14}$ Nevertheless, concerns have been raised on the accuracy of this surge in numbers of reported cases of microcephaly. There have been several opinion pieces suggesting that the numbers are overinflated as a result of the heightened 'awareness' effect (reporting cases that would have gone unnoticed under normal circumstances), using different criteria and screening tests that have low specificity, suggesting the possibility that there may be an overestimation of actual number of cases, as normal births would have invariably been included. ${ }^{19}$ Further concerns have also been brought up by a very recent 'WHO Bulletin' report ${ }^{20}$ which suggest that there had already been fluctuations in the number of cases in Brazil since 2012, even before the recorded entry of the Zika virus to the continent. The research from Brazil had analysed data of microcephalic cases from 2012-2015, using three different criteria, and observed fluctuations in numbers over the years with peaks at the end of 2012 and mid-2014. Other causes contributing to microcephaly have also been suggested - such as exposure to various teratogens during early pregnancy including toxins, drugs, alcohol, vaccines, and infections, which may include STORCH (syphilis, toxoplasmosis, rubella, cytomegalovirus and herpes virus) syndrome and the possibility of co-infection with other agents such as dengue and chikungunya. ${ }^{20}$

\section{GUILLAIN-BARRÉ SYNDROME}

Regarding GBS, Brazil, Colombia, El Salvador, Suriname and Venezuela have all reported an increase in GBS cases. Brazil reported 1,708 cases in 2015 and 1,439 cases in 2014, representing an increase of 19\%. Colombia, which normally saw 242 cases of GBS annually, has already reported 86 GBS cases in the first weeks of 2016, ending January 2016. ${ }^{14}$ In an alarming turn of events, Colombia's National Health Institute reported the first Zika-related deaths in three patients who succumbed after contracting the virus and developing complications related to Guillain-Barré syndrome (http:// www.theguardian.com/world/2016/feb/04/ colombia-zika-virus-first-deaths-patients).
Craniofacial or other head and neck manifestations have not been reported, although, recent data from an eye hospital in Recife (Fundação Altino Ventura) Brazil which examined 10 children born with microcephaly reported ophthalmological manifestations including optic nerve (optic nerve hypoplasia) and macular (pigment mottling, chorioretinal atrophy) alterations. ${ }^{21}$ In addition, a recent report also from Recife showed the first intrauterine transmission of ZIKV, including a possible disease association, arthrogryposis, a rare disease characterised by severe deficiency in the joints. ${ }^{22}$ Thrombocytopenia is another possibility reported after preparation of this review.

\section{DIAGNOSIS AND PREVENTION OF ZIKA}

The diagnosis of ZIKV infection can be confirmed by molecular and serologic testing including a reverse transcription-polymerase chain reaction (RT-PCR) for Zika RNA, and immunoglobulin (IgM) ELISA (Enzyme Linked Immunosorbent Assay) and Plaque Reduction Neutralisation Test (PRNT) for Zika virus antibodies. ${ }^{23}$ No specific antiviral treatment is available for ZIKV infections and no vaccine against Zika virus is available (http://www. who.int/mediacentre/factsheets/zika/en/).

Prevention against mosquito bites (particularly daytime bites) is best offered by avoiding mosquitoes and bites by wearing clothing with long arms and legs, using nets in bed, and always leaving skin as little exposed but covered with mosquito repellants, ${ }^{24}$ mainly ethyl butylacetylaminopropionate (EBAAP). This is also recommended for children from six months to two years of age. DEET (N,N-diethyl-meta-toluamide), although safe for pregnant women, should not be used for children less than two years of age; and Icaridin which has been the first option for adults and pregnant women, since this repellent offers up to ten hours of protection, but cannot be used in children younger than two years of age.

Recent CDC (US Centres for Disease Control and Prevention) guidelines for healthcare providers in the United States for prevention of sexual transmission of Zika virus and caring for pregnant women during a Zika virus outbreak have been issued. These include recommendations for screening pregnant women who are considering travelling to an area with ZIKV transmission and recommendations for the testing and management of pregnant returning travellers. ${ }^{25,26}$ Health care providers should ask all pregnant women about recent travel. Pregnant women with a history of travel to an area with Zika virus transmission and who report two or more symptoms consistent 
with Zika virus disease during or within two weeks of travel, or who have ultrasound findings of fetal microcephaly or intracranial calcifications, should be tested for ZIK $^{27}$.

\section{Authors note}

Since acceptance in early February, another useful paper has appeared; Shakib K. Epidemic of Zika virus and maxillofacial surgery. Br J Oral Maxillofac Surg (2016), http://dx.doi.org/10.1016/j. bjoms.2016.02.001

1. Van Herck K, Van Damme P, Castelli F et al. Knowledge, attitudes and practices in travel-related infectious diseases: the European airport survey. J Travel Med 2004: 11: 3-8.

2. Ayres CFJ. Identification of Zika virus vectors and implications for control. Lancet Infect Dis 2016; DOI:10.1016/S1473-3099(16)00073-6.

3. Cao-Lormeau V M, Muso D. Emerging arboviruses in the Pacific. Lancet 2014; 384: 1571-1572.

4. Guzman M G, Harris E. Dengue. Lancet 2015; 385: 453-465.

5. Samarasekera U, Triunfol M. Concern over Zika virus grips the world. Lancet 2016; 387: 521-524

6. Musso D, Nhan T, Robin E et al. Potential for Zika virus transmission through blood transfusion demonstrated during an outbreak in French Polynesia, November 2013 to February 2014. Euro Surveill 2014: 19: 20771.

7. Bernard M, Lastere S, Teissier A, Cao-Lormeau V M, Musso D. Evidence of perinatal transmission of Zika virus, French Polynesia, December 2013 and February 2014. Euro Surveill 2014; 19: 20751.
8. Musso D, Roche C, Robin E et al. Potential sexual transmission of Zika virus. Emerg Infect Dis 2015; 21: 359-361.

9. Dallas County, Department of Health and Human Services. Health advisory: Sexual transmission of Zika virus. 2016. Available online at http://www. dallascounty.org/department/hhs/documents/ DCHHS_Zika_HealthAdvisory_20160202_final.pdf (accessed February 2016).

10. Musso D, Roche D, Nhan T et al. Detection of Zika virus in saliva. J Clin Virol 2015; 68: 53-55.

11. Hayes EB. Zika virus outside Africa. Emerg Infect Dis 2009; 15: 1347-1350.

12. Duffy M R, Chen TH, Hancock W T et al. Zika virus outbreak on Yap Island, Federated States of Micronesia. N Engl J Med 2009; 360: 2536-2543.

13. Tognarelli J, Ulloas S, Villagra E et al. A report on the outbreak of Zika virus on Easter Island, South Pacific, 2014. Arch Virol 2015 Nov 26. [Epub ahead of print].

14. WHO. Zika situation report. Available online at http://apps.who.int/iris/bitstream/10665/204348/1/ zikasitrep_5Feb2016_eng.pdf?ua=1. (accessed February 2016).

15. Attar N. Zika virus circulates in new regions. Nat Rev Microbiol 2016: 14: 62

16. Fauci A S, Morens D M. Zika virus in the Americasyet another arbovirus threat. N Eng/ J Med. 2016; 374: 601-604.

17. Bogoch I I, Brady 0 J, Kraemer M U et al. Anticipating the international spread of Zika virus from Brazil. Lancet. 2016; 387: 335-336.

18. Tetro J A. Zika and microcephaly: Causation, correlation, or coincidence? Microbes Infect. 2016: D0I:10.1016/j.micinf.2015.12.010.

19. Victora C G, Schuler-Faccini L, Matijasevich A et al.
Microcephaly in Brazil: how to interpret reported numbers? Lancet 2016; DOI:10.1016/S01406736(16)00273-7.

20. Soares de Araújo J S, Regis C T, Gomes RG S et al. Microcephaly in northeast Brazil: a review of 16 208 births between 2012 and 2015. Bull World Health Organ 2016; DOI: 10.2471/BLT.16.170639.

21. Ventura CV, Maia M, Ventura B V et al. Ophthalmological findings in infants with microcephaly and presumable intra-uterus Zika virus infection. Arq Bras Oftalmol 2016; 79: 1-3.

22. Oliviero Melo A S, Malinger G, Ximenes $R$ et al. Zika virus intrauterine infection causes fetal brain abnormality and microcephaly: tip of the iceberg. Physician Alert Ultrasound Obstet Gynecol 2016; 47: 6-7.

23. Staples J E, Dziuban E J, Fischer M et al. Interim guidelines for the evaluation and testing of infants with possible congenital Zika virus infection United States, 2016. MMWR Morb Mortal Wkly Rep 2016; 65: 63-67.

24. PAHO. Statement on Zika virus transmission and prevention. Available online at http://www.paho. org/hq/index.php?option=com_contentEtview=articlectid=11605Etlt. (accessed February 2016).

25. CDC. Travel health notices. http://wwwnc.cdc.gov/ travel/notices. (accessed February 2016).

26. Oster A M, Brooks J T, Stryker J E et al. Interim guidelines for prevention of sexual transmission of Zika virus - United States, 2016. MMWR Morb Mortal Wkly Rep 2016; 65: 1-2.

27. Oduyebo T, Petersen E E, Rasmussen $S A$ et al. Update: Interim guidelines for health care providers caring for pregnant women and women of reproductive age with possible Zika virus exposure United States, 2016. MMWR Morb Mortal Wkly Rep 2016; 65: 1-6. 